DOI: 10.12731/2658-4034-2020-2-32-38

\title{
ОСОБЕННОСТИ ЛИЧНОСТНОГО \\ АДАПТАЦИОННОГО ПОТЕНЦИАЛА У ЛИЦ СРЕДНЕГО ВОЗРАСТА В УСЛОВИЯХ СОЦИАЛЬНОЙ ИЗОЛЯЦИИ, СОВЕРШИВШИХ ПРЕСТУПЛЕНИЕ ПРОТИВ ЛИЧНОСТИ
}

\author{
Богданова Е.А., Губин В.А.
}

Ленинградский государственный университет им. А.С. Пушкина, г. Санкт-Петербург, Российская Федерация

В статье рассматриваются теоретические и прикладные вопросы изучения адаптационного потенцииала у лиц среднего возраста, находящихся в условиях социальной изоляции.

Ключевые слова: средний возраст; сочиальная изоляция; осужденные; личностный адаптационный потенциал; поведенческая регулячия; моральная нормативность; коммуникативные способности.

\section{COMPARATIVE ANALYSIS OF PERSONAL ADAPTIVE POTENTIAL IN MIDDLE-AGED PEOPLE IN CONDITIONS OF SOCIAL ISOLATION}

\author{
Bogdanova E.A., Gubin V.A. \\ Leningrad State University named after A.S. Pushkin, \\ St. Petersburg, Russian Federation
}

The article discusses theoretical and applied issues of studying the adaptive potential of middle-aged people who are in conditions of social isolation.

Keywords: middle age; social isolation; convicts; personal adaptive potential; behavioral regulation; moral normativeness; communication skills. 


\section{Введение}

Исследование личности очень сложный и интересный процесс, он позволяет раскрыть многогранность и уникальность каждого отдельного индивида. Многие авторы занимались и занимаются изучением особенностей личности. Мы приведем только некоторые наиболее яркие фамилии: E.S. Fromm, Л.С. Выготский, Г. Айзенк, С.Л. Рубинштейн, А.Г. Ковалев, В.Н. Мясищев, S. Freud, C. Rogers, Н.A. Murray, A. Maslow, Б.Г. Ананьев, Л.И. Божович, А.Н. Леонтьев, В.А. Петровский и др.

Исследование личности в условиях социальной изоляции позволит повысить эффективность воспитательной работы исправительных учреждений. Благодаря таким исследованиям разрабатываются новые, более совершенные подходы к воспитанию данного контингента. Основной целью исправительных колоний является ресоциализация и последующее возвращение к наиболее социально-приемлемому образу жизни бывших осужденных.

Нахождение в условиях социальной изоляции независимо от возрастных характеристик и сроков пребывания в исправительной колонии оказывает влияние на поведение индивида. Попадая в такие условия, индивид очень сильно меняет сложившийся до этого уклад жизни, ценностные ориентации, копинг-стратегии поведения. Желания, потребности, интересы индивида не могут быть удовлетворены в полном объеме, и на их удовлетворение тратится значительное количество адаптационных ресурсов, что приводит к росту эмоционального напряжения и фрустрации. Уникальность человеческой психики не позволяет создать универсальный стандарт воспитательной работы с данным контингентом. В таких условиях проявляются с особой остротой реакции на социальную изоляцию, акцентуации характера. Каждый человек по-своему переживает возникающие стрессы.

Нахождение в условиях социальной изоляции заставляет индивида постоянно прибывать в состоянии ожидания. Это состояние может сопровождаться тревогой, страхом и нетерпением. В условиях лишения свободы к индивиду предъявляют повышенные требования к адаптивности психики. 
В этой связи актуальным является совершенствование процесса психологического сопровождения лиц среднего возраста, находящихся в условиях социальной изоляции.

В основе работы лежит представление об адаптации как о непрерывном процессе, где индивид активно пытается приспособиться на биологическом уровне к постоянно изменяющимся условиям нахождения в исправительной колонии, а на социальном уровне присвоить требования администрации данного учреждения к поведению и деятельности. На эффективность процесса адаптации влияют адекватность самовосприятия, восприятия социального окружения, своих потребностей и имеющихся возможностей, а также осознание мотивов своего поведения. Нарушения адаптации приводят к ухудшению состояния здоровья, конфликтным ситуациям и нарушению взаимоотношений в социуме, а также к снижению работоспособности [4].

\section{Материалы и методы исследования}

В своей работе мы использовали многоуровневый личностный опросник (МЛО) «Адаптивность». Данный опросник был разработан А.Г. Маклаковым и С. В. Чермяниным (1993 г.). Этот метод предназначен для исследования адаптивных возможностей индивида.

Многоуровневый личностный опросник (МЛО) «Адаптивность» состоит из 165 вопросов и имеет 4-е структурных уровня. В своей работе мы использовали шкалы 3-го и 4-го уровня:

- Шкалы 3-го уровня: поведенческая регуляция (ПР), коммуникативный потенциал (КП) и моральная нормативность (МН).

- Шкала 4-го уровня - личностный адаптационный потенциал (ЛАП).

Используя методику «Адаптивность» (МЛО) нами были обследованы две группы испытуемых: в экспериментальную группу вошли, лица среднего возраста находящиеся в условиях социальной изоляции, осуждённые по статьям 105 (убийство) Федерального казенного учреждения Исправительной колонии №7 по Санкт-Петербургу и Ленинградской области, в количестве 50 человек. Контрольную 
группу составили, лица ранее не привлекавшиеся к уголовной ответственности, в количестве 40 человек, работники Совмещенного трамвайно - троллейбусного парка (СТТП) №10.

\section{Результаты исследования}

Полученные в процессе исследования данные подвергались математико-статистической обработке с помощью параметрического критерия t-Стьюдента и непараметрического критерия U-Манна-Уитни.

Сравнительный анализ экспериментальной и контрольной групп свидетельствует о том, что показатели «Личностного адаптационного потенциала» (ЛАП) $(\mathrm{t}=4,541, \mathrm{p}=0,000)$, «Поведенческой регуляции» $($ ПР) $(\mathrm{t}=4,598, \mathrm{p}=0,000)$ и «Моральной нормативности» $(\mathrm{MH})$ $(\mathrm{t}=4,324, \mathrm{p}=0,000)$ в экспериментальной группе имеют удовлетворительный уровень, в отличие от контрольной группы, которая обладает высоким уровнем адаптационного потенциала (Таблица 1).

Сравнительный анализ показателей «Личностного адаптационного потенциала», «Поведенческой регуляции» и «Моральной нормативности» между группой осужденных по статье 105 и группой лиц ранее не привлекавшихся к уголовной ответственности

\begin{tabular}{|l|l|l|l|l|}
\hline \multicolumn{1}{|c|}{ Признак } & $\begin{array}{c}\text { Осужден- } \\
\text { ные по } \\
\text { ст.105 } \\
\text { Мх } \pm \mathrm{m}\end{array}$ & $\begin{array}{c}\text { Лица ранее не } \\
\text { привлекавшиеся к } \\
\text { уголовной ответ- } \\
\text { ственности Мх } \pm \mathrm{m}\end{array}$ & $\begin{array}{c}\text { Значе- } \\
\text { ние } \\
\text { t-Стью- } \\
\text { дента }\end{array}$ & $\begin{array}{c}\text { Уровень } \\
\text { значимо- } \\
\text { сти разли- } \\
\text { чий (р=) }\end{array}$ \\
\hline $\begin{array}{l}\text { Личностный адаптаци- } \\
\text { онный потенциал (ЛАП) }\end{array}$ & $59,92 \pm 2,75$ & $41,08 \pm 3,12$ & 4,541 & 0,000 \\
\hline $\begin{array}{l}\text { Поведенческая регуля- } \\
\text { ция (ПР) }\end{array}$ & $33,64 \pm 2,16$ & $19,63 \pm 2,08$ & 4,598 & 0,000 \\
\hline $\begin{array}{l}\text { Моральная норматив- } \\
\text { ность (МН) }\end{array}$ & $11,68 \pm 0,46$ & $8,63 \pm 0,55$ & 4,324 & 0,000 \\
\hline
\end{tabular}

Сравнительный анализ экспериментальной и контрольной групп свидетельствует о том, что статистически достоверно у осужденных по статье 105 средний ранг показателя «Коммуникативный потенциал» $(\mathrm{U}=809,500, \mathrm{p}=0,121)$ выше, чем у лиц ранее не привлекавшихся к уголовной ответственности, что говорит о низком уровне развития у испытуемых коммуникативных навыков (Таблица 2). 
Таблица 2.

Сравнительный анализ по показателю «Коммуникативный потенциал» между группой осужденных по статье 105 и группой лиц ранее не привлекавшихся к уголовной ответственности

\begin{tabular}{|c|c|c|c|c|c|c|}
\hline \multirow{2}{*}{ Признак } & \multicolumn{2}{|c|}{$\begin{array}{c}\text { Осужденные по } \\
\text { статье } 105\end{array}$} & $\begin{array}{c}\text { Лица ранее не } \\
\text { привлекавшиеся } \\
\text { к уголовной от- } \\
\text { ветственности }\end{array}$ & $\begin{array}{c}\text { Значение } \\
\text { U-Манна- } \\
\text { Уитни }\end{array}$ & $\begin{array}{c}\text { Уровень } \\
\text { значимо- } \\
\text { сти разли- } \\
\text { чий (p=) }\end{array}$ \\
\cline { 2 - 5 } & $\begin{array}{c}\text { Средний } \\
\text { ранг }\end{array}$ & $\begin{array}{c}\text { Сумма } \\
\text { рангов }\end{array}$ & $\begin{array}{c}\text { Средний } \\
\text { ранг }\end{array}$ & $\begin{array}{c}\text { Сумма } \\
\text { рангов }\end{array}$ & \\
\cline { 1 - 5 } $\begin{array}{l}\text { Коммуникативный } \\
\text { потенциал (КП) }\end{array}$ & 49,31 & 2465,50 & 40,74 & 1629,50 & 809,500 & 0,121 \\
\hline
\end{tabular}

\section{Обсуждение}

Данные полученные с помощью методики (МЛО) «Адаптивность», являются обратными, высокий балл по показателю несет в себе низкое значение параметра.

Таким образом, экспериментальная группа имеет удовлетворительный «Личностный адаптационный потенциал». У данной группы испытуемых наблюдаются присутствия акцентуаций характера, которые в привычных условиях частично компенсированы и могут проявляться при смене деятельности. При таком показателе ЛАП, можно наблюдать нервно-психические срывы, выраженные признаки агрессии и конфликтности, проявление асоциального поведения.

Удовлетворительный характер, в экспериментальной группе, носит показатель «Поведенческой регуляции», обусловленный умеренным нарушениям психической деятельности. В экстремальной ситуации, поведение испытуемых, может, отличатся неадекватностью и неверным восприятием окружающей действительности.

«Моральная нормативность» у экспериментальной и контрольной групп расценивается как удовлетворительная. При этом у экспериментальной группы, отмечаются более низкие значения параметра, что говорит о слабой оценке своего места и роли в коллективе и о низком соблюдении и принятии общепринятых норм поведения.

На низком уровне, в экспериментальной группе, находится показатель «Коммуникативного потенциала». Обследуемые испытывают трудности при взаимодействии с окружающими, также им свойственна повышенная конфликтность и агрессивность. 


\section{Заключение}

В результате исследования было выявлено, что группа испытуемых в условиях социальной изоляции обладает удовлетворительным личностным адаптационным потенциалом к условиям социальной изоляции. «Поведенческая регуляция», отвечающая за взаимодействие индивида со средой и «Моральная нормативность» подразумевающая под собой восприятие морально-нравственных норм поведения и отношение к требованиям социального окружения, у осужденных по статье 105, также имеют удовлетворительный уровень. «Коммуникативные способности» у осужденных по статье 105, которые предполагают умение достигнуть контакта и взаимопонимания с окружающими, на низком уровне.

Таким образом, психологам учреждения необходимо разработать коррекционные методы, направленные на повышение коммуникативных способностей, принятие норм поведения в исправительном учреждении, направленных на регуляцию моральной нормативности. В результате проведенной работы с осужденными по статье 105 существует необходимость осуществлять коррекционные мероприятия и в других направлениях: по снижению возбудимости, агрессивности, тревожности, урегулированию эмоциональных состояний, снятию нервно-психической напряженности.

Информация о конфликте интересов. В ходе исследования конфликт интересов у осужденных исправительного учреждения не выявлен.

Информация о спонсорстве. Исследование не имело спонсорской поддержки.

\section{Список литературы}

1. Губин В.А. Психология трудовой деятельности закрытых коллективов: автореферат дис. ... доктора психологических наук: 19.00.03 / С.-Петерб. гос. ун-т. - Санкт-Петербург, 1996. 32 с.

2. Губин В.А., Ахмедханов М.А., Андреевский Е.В. Модель выявления психологических характеристик, способствующих совершению несанкционированных действий военнослужащими внутренних войск 
МВД России, охраняющих ядерно-опасный объект / Армия и общество. 2015. №3 (46). С. 22-32.

3. Губин В.А., Ахмедханов М.А. Прогнозирование успешности профессиональной деятельности специалистов в области охраны важных государственных объектов на этапе обучения в учебном центре внутренних войск / Научно-информационный журнал Армия и общество. 2013. №5. С. 64-68.

4. Дмитриев Ю.А. Пенитенциарная психология / Ю.А. Дмитриев, Б.Б. Казак. Ростов н/Д.: Феникс, 2007. 681 с.

5. Еникеев М.И. Общая, социальная и юридическая психология: Учебник для вузов / М. Еникеев. СПб.: Питер, 2003. 752 с.

6. Ермолаева М. В. Основы возрастной психологии и акмеологии: Учеб. пособие / М.В. Ермолаева. М.: Ось-89, 2003. 414 с.

7. Маклаков А.Г. Общая психология. СПб.: Питер, 2001. 592 с.

\section{References}

1. Gubin V.A. Psihologiya trudovoj deyatel'nosti zakrytyh kollektivov: avtoreferat dis. ... doktora psihologicheskih nauk: 19.00.03 / S.-Peterb. gos. un-t. Sankt-Peterburg, 1996. 32 s.

2. Gubin V.A., Ahmedhanov M.A., Andreevskij E.V. Model' vyyavleniya psihologicheskih harakteristik, sposobstvuyushchih soversheniyu nesankcionirovannyh dejstvij voennosluzhashchimi vnutrennih vojsk MVD Rossii, ohranyayushchih yaderno-opasnyj ob»ekt / Armiya i obshchestvo.2015. №3 (46).

3. Gubin V.A., Ahmedhanov M.A. Prognozirovanie uspeshnosti professional'noj deyatel'nosti specialistov v oblasti ohrany vazhnyh gosudarstvennyh ob»ektov na etape obucheniya v uchebnom centre vnutrennih vojsk / Nauchno-informacionnyj zhurnal Armiya i obshchestvo.2013.№5. S. 64-68.

4. Dmitriev Yu.A. Penitenciarnaya psihologiya / Yu.A. Dmitriev, B.B. Kazak. Rostov n/D.: Feniks, 2007. $681 \mathrm{~s}$.

5. Enikeev M.I. Obshchaya, social'naya i yuridicheskaya psihologiya: Uchebnik dlya vuzov / M. Enikeev. SPb.: Piter, 2003. 752 s.

6. Ermolaeva M.V. Osnovy vozrastnoj psihologii i akmeologii: Ucheb. posobie / M.V. Ermolaeva. M.: Os'-89, 2003. 414 s.

7. Maklakov A.G. Obshchaya psihologiya. SPb.: Piter, 2001. $592 \mathrm{~s}$. 